\title{
Transcranial versus Endoscopic Transsphenoidal Approaches in Management of Recurrent Giant Pituitary Adenomas
}

\author{
Mohamed Ismail $^{\star}$, Omar Abdel Aleem Abdel Moneim Ragab, Mohamed M. Salama, Basim M. Ayoub, Wael Elmahdy \\ Faculty of Medicine, Cairo University, Giza, Cairo, Egypt
}

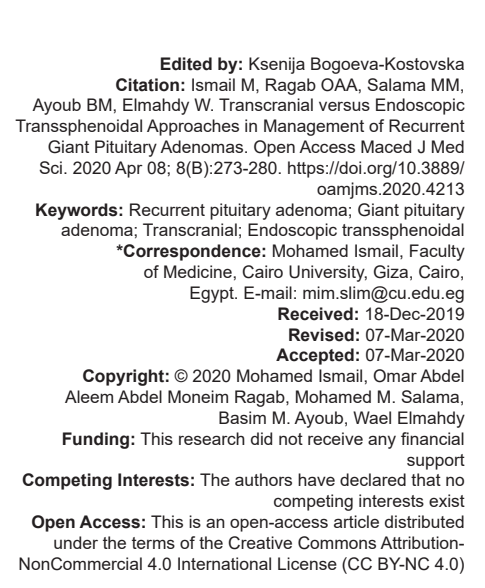

\begin{abstract}
AIM: The aim of this study was to compare the transcranial and the endoscopic transsphenoidal approaches for patients with recurrent giant pituitary adenomas as regards the extent of tumor resection and the clinical outcome.

METHODS: The study included 21 patients with recurrent giant pituitary adenomas divided into two groups; Group A included nine patients operated on by transcranial approaches and Group B included 12 patients operated on by the endoscopic transsphenoidal approach. Both groups were compared as regards the extent of tumor resection and the post-operative clinical outcome, particularly the visual and endocrinological outcomes, in addition to morbidity and mortality.

RESULTS: There was a higher incidence of total and near-total resection in Group B (41.7\%) and a higher incidence of subtotal resection in Group A (55.6\%). The incidence of visual improvement was higher in Group B (55.6\%) than in Group A (28.6\%). Post-operative biochemical remission was achieved in $100 \%$ of Group B patients and in $50 \%$ of Group A patients with functioning adenomas. The incidence of post-operative complications was higher in Group A $(77.8 \%)$ than in Group B (50\%).

CONCLUSION: The endoscopic transsphenoidal approach for recurrent giant pituitary adenomas is associated with a higher extent of tumor resection, better rates of visual improvement and endocrinological remission, and lower incidence of complications. The transcranial approach should be reserved for some adenomas with marked lateral or anterior extensions, fibrous tumors, and after the failure of the endoscopic transsphenoidal approach.
\end{abstract}

\section{Introduction}

Giant pituitary adenomas are adenomas exceeding $3-4 \mathrm{~cm}$ in their largest diameter [1], [2], [3], [4], [5]. They represent around $5-15 \%$ of all pituitary adenomas [2], [4]. Due to their large size, giant adenomas usually present with manifestations due to mass effect, particularly visual affection, with or without manifestations due to hormonal disturbances. Other presentations include headache, pituitary apoplexy, and hydrocephalus (HCP) [6], [7], [8], [9]. Recurrent giant adenomas are usually nonfunctioning adenomas or prolactin-secreting adenomas, and less commonly to be growth hormone $(\mathrm{GH})$-secreting or adrenocorticotrophic hormone (ACTH)-secreting adenomas [4], [8], [9], [10].

Some patients with recurrent giant adenomas may benefit from medical treatment; however, the majority of the patients will need reoperation and/or radiation [5], [7], [11]. Whenever possible, aggressive surgical resection is warranted to avoid the need for post-operative radiation if possible or to improve the response and decrease the hazards of radiation if needed by decreasing the volume of post-operative residual [12]. Unfortunately, radical resection of these challenging cases is difficult to be achieved in many cases, thus multimodal treatment with surgery, radiation and/or medical treatment might be needed in patients with residual tumors for better tumor control and lower recurrence rate [5], [6], [7], [9], [11].

The choice of surgical approach depends on several factors, including the tumor's extensions and consistency, the approach used in the initial surgery, and thesurgeon'sexperienceand preference[7], [8],[13],[14]. Endoscopic transsphenoidal approaches, transcranial approaches, and combinations of both, whether simultaneously or staged, have been reported for the management of these challenging cases with variable outcomes. However, these reports were not focusing on recurrent giant adenomas in particular. Some of these articles were addressing recurrent adenomas irrespective of the size [15], [16], while others were addressing the different surgical approaches for giant adenomas whether fresh or recurrent [8], [9], [17].

The objective of this study was to compare the transcranial and the endoscopic transsphenoidal approaches in a group of patients with recurrent giant pituitary adenomas regarding the extent of tumor resection and the clinical outcome, particularly the visual and endocrinological outcomes. 


\section{Patients and Methods}

This study included 21 patients with recurrent giant pituitary adenomas who were operated on in Cairo University Hospitals in the period between March 2017 and March 2019 by both transcranial and transsphenoidal approaches. Giant adenomas were considered as adenomas $>3 \mathrm{~cm}$ in the largest tumor diameter, while recurrence was considered as the reappearance of a totally resected tumor or regrowth of a residual tumor. All patients were indicated for surgical resection due to progressive neurological deterioration, manifestations of hormonal disturbance, and/or other clinical presentations, including headache. Recurrent adenomas $<3 \mathrm{~cm}$ in diameter, giant nonrecurrent adenomas, recurrent prolactinomas responding to medical treatment, and patients unfit or unwilling for surgical intervention were excluded from the study.

All patients were subjected to thorough history taking and detailed clinical examination with special emphasis on assessment of visual acuity, ocular motility, visual field assessment by confrontation and fundus examination in addition to examination for features of acromegaly or gigantism, features of Cushing syndrome, assessment of secondary sexual characters, and examination for galactorrhea in females. Investigations included automated perimetry for visual field assessment, the hormonal profile including serum prolactin with serial dilution to exclude hook effect, $\mathrm{GH}$, $\mathrm{ACTH}$, morning and evening cortisol, thyroid-stimulating hormone (TSH), triiodothyronine (T3), thyroxin (T4), follicle-stimulating hormone, luteinizing hormone, and testosterone levels in addition to routine pre-operative laboratory investigations. Magnetic resonance imaging (MRI) sella with contrast was performed for all patients while computed tomography (CT) paranasal sinuses was performed for patients planned for transsphenoidal approach.

Patients were divided into two groups according to the surgical approach performed; Group A included nine patients who were operated on by the transcranial approaches and Group B included 12 patients who were operated on by the endoscopic transsphenoidal approach. The choice of the approach was based on multiple factors, including tumor's configuration and extensions, especially lateral and anterior extensions, the tumor's suspected consistency, the previously used surgical approach, and the surgeon's experience and preferences. The tumor's extensions into various compartments were demonstrated on MRI. The firm consistency of the tumor could be predicted using different MRI sequences as T2-weighted images and diffusion-weighted images. Some surgeons preferred a transcranial approach following an initial transsphenoidal approach to avoid going through adhesions and distorted anatomical landmarks, while others preferred a transcranial approach when they suspected preoperatively that the tumor extensions and consistency would be difficult to reach and manage through the transsphenoidal approach. Surgeons with more familiarity with the transsphenoidal approaches have preferred to use it, especially when the lesion had no or minimal parasellar extension. Surgeons' preference was one of the important factors affecting the choice of the approach.

Post-operative evaluation stressed on assessment of conscious level, visual acuity and field, cranial nerves, motor power, hypothalamic manifestations, or other neurological deficits. Morbidity in the form of cerebrospinal fluid (CSF) leak, infection, visual and neurological deficits, diabetes insipidus (DI), and other endocrinopathies were recorded. The cause and timing of mortality were also documented. Hormonal assay was obtained in the early postoperative period and endocrinological remission was assessed in patients with functioning adenomas. Patients with endocrinopathies were referred to an endocrinologist. An early post-operative CT scan or MRI was performed before discharge. MRI sella with contrast was performed 3 months after surgery when immediate post-operative MRI was not performed to determine the extent of resection.

Patients were followed up in the outpatient clinic for 1 month and 3 months after surgery. The outcome was assessed as regards the extent of resection (primary outcome), the clinical outcome, especially the visual outcome, the endocrinological remission, and the incidence of morbidity and mortality (secondary outcomes). The extent of tumor resection was categorized based on the post-operative MRI into total or near-total resection $(>90 \%)$, subtotal resection $(70-90 \%)$, and partial resection $(<70 \%)$. The endocrinological outcome in patients with functioning adenomas was categorized as cured if the serum hormone level was normalized, improved if there was $>50 \%$ reduction of the preoperative serum hormone level, and unchanged if reduction was $<50 \%$.

\section{Statistical methods}

Data of patients were coded and entered using the Statistical Package for the Social Sciences version 25. Data were summarized using mean, standard deviation, median, minimum, and maximum for quantitative data and using frequency (count) and relative frequency (percentage) for categorical data. Comparisons between quantitative variables were done using the nonparametric Mann-Whitney test. For comparing categorical data, Chi-square test was performed. Exact test was used instead when the expected frequency was $<5 . P<0.05$ was considered as statistically significant. 


\section{Results}

This prospective study included 21 patients with recurrent giant pituitary adenomas who were divided into two groups according to the performed surgical approach. Group A included nine patients who were operated on by the transcranial approaches and Group B included 12 patients who were operated on by the endoscopic transsphenoidal approach. Patients' demographics, data of previous treatments, and tumors' types are summarized in Table 1.

Table 1: Patients' demographics, data of previous treatments, and tumors' types

\begin{tabular}{|c|c|c|c|}
\hline & Group A & Group B & $p$ value \\
\hline \multicolumn{4}{|l|}{ Gender } \\
\hline Male & $5(55.6 \%)$ & $8(66.7 \%)$ & \multirow[t]{2}{*}{0.673} \\
\hline Female & $4(44.4 \%)$ & $4(33.3 \%)$ & \\
\hline \multicolumn{4}{|l|}{ Age (years) } \\
\hline Minimum & 23 & 24 & \multirow[t]{3}{*}{0.651} \\
\hline Maximum & 64 & 65 & \\
\hline Mean & 47.11 & 43.75 & \\
\hline \multicolumn{4}{|c|}{ Number of previous surgeries } \\
\hline 1 & 7 & 9 & \multirow[t]{3}{*}{0.472} \\
\hline 2 & 2 & 1 & \\
\hline 3 & - & 2 & \\
\hline \multicolumn{4}{|c|}{ Interval since last surgery (years) } \\
\hline Minimum & 1 & 1 & \multirow[t]{3}{*}{0.651} \\
\hline Maximum & 7 & 6 & \\
\hline Mean & 3.89 & 3.5 & \\
\hline \multicolumn{4}{|l|}{ Previous route } \\
\hline Transsphenoidal & $6(66.7 \%)$ & $9(75.0 \%)$ & \\
\hline Transcranial & $3(33.3 \%)$ & $3(25.0 \%)$ & \\
\hline \multicolumn{4}{|l|}{ Previous radiation } \\
\hline Yes & 1 & - & \\
\hline No & 8 & 12 & \\
\hline \multicolumn{4}{|c|}{ Previous medical treatment } \\
\hline Yes & 2 & 1 & \\
\hline No & 7 & 11 & \\
\hline \multicolumn{4}{|l|}{ Type of adenoma } \\
\hline Non-functioning & $7(77.8 \%)$ & $9(75.0 \%)$ & 0.472 \\
\hline Prolactinoma & $2(22.2 \%)$ & $1(8.3 \%)$ & \\
\hline GH-secreting & 0 & $2(16.7 \%)$ & \\
\hline
\end{tabular}

The clinical presentations of the patients in both groups are shown in Figure 1.

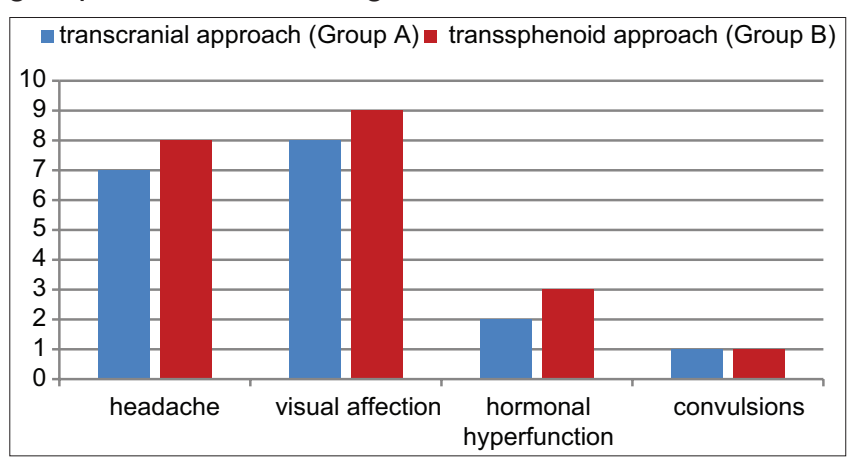

Figure 1: Chart showing clinical presentations in both groups

One of the important factors that influenced the choice of the operative approach was the extensions of the tumor into the various nearby compartments. Figure 2 shows the various tumors' extensions in both groups. A significant extension of the adenoma into the parasellar region, particularly lateral or superolateral to the cavernous sinus into the middle fossa, favored the choice of the transcranial approach. Similarly, significant tumor extension into the anterior cranial fossa favored the choice of the transcranial approach. On the other hand, cavernous sinus invasion did not favor an approach over the other.

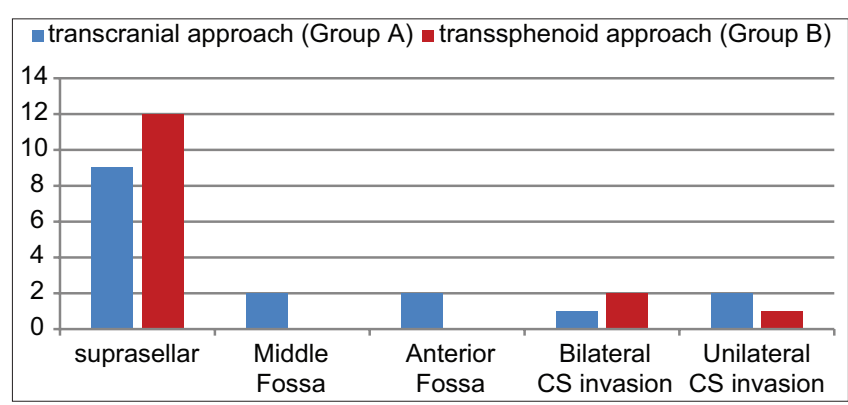

Figure 2: Chart showing tumor extensions in both groups

All patients in Group A were operated on by the pterional approach and its modifications; six patients from the right side and three patients from the left side. Three of these patients have been previously operated on by a transcranial approach, right pterional approach in one patient, left pterional approach in one patient, and right subfrontal approach in the third patient. All three patients were approached from the same side of the previous approach with the craniotomy flap enlarged in the patient with previous subfrontal approach into a frontotemporal craniotomy. All patients in Group B were operated on by the conventional endoscopic endonasal transsphenoidal approach without the use of navigation; nine of them have been operated on by the endoscopic transsphenoidal approach in the primary surgery.

The extent of resection in both groups is shown in Table 2. The limitations to radical resection in our series included cavernous sinus invasion, significant anterior or middle fossa extensions, marked suprasellar extension into the third ventricle, and firm consistency. Factors hindering gross total resection included cavernous sinus invasion in six cases, marked suprasellar, middle fossa or anterior fossa extension in seven cases, and firm consistency in five cases, with more than one factor being present some cases. These factors especially the marked extension into the anterior or the middle cranial fossa and the firm consistency made the extent of resection lower in the cases operated on using the transcranial approach (Group A).

Table 2: Extent of tumor resection in both groups

\begin{tabular}{|c|c|c|c|c|c|c|c|}
\hline \multirow[t]{2}{*}{ Extent of resection } & \multicolumn{2}{|c|}{ Group A } & \multicolumn{2}{|c|}{ Group B } & \multicolumn{2}{|c|}{ Total } & \multirow[t]{2}{*}{$\mathrm{p}$-value } \\
\hline & $\mathrm{n}$ & $\%$ & $n$ & $\%$ & $\mathrm{n}$ & $\%$ & \\
\hline Total and near total & 1 & 11.1 & 5 & 41.7 & 6 & 28.6 & 0.185 \\
\hline Subtotal & 5 & 55.6 & 3 & 25 & 8 & 38.1 & \\
\hline Partial & 3 & 33.3 & 4 & 33.3 & 7 & 33.3 & \\
\hline
\end{tabular}

As regards the visual outcome, two of the seven surviving patients $(28.6 \%)$ with pre-operative visual affection in Group A showed improvement while five patients $(71.4 \%)$ remained stationary, and there was no visual deterioration in any patient. Five of the nine (55.6\%) patients with pre-operative visual affection in Group B showed improvement, while four patients (44.4\%) remained stationary, and there was no visual deterioration in any patient. The incidence of visual improvement in the whole study group was $43.8 \%$. Headache was the 
presenting symptom in seven patients in Group A and in eight patients in Group B. All of the patients showed improvement in their headaches postoperatively.

Regarding functioning adenomas, normalization of the hormonal level was achieved in $100 \%$ of the patients with $\mathrm{GH}$-secreting adenomas and in $66.7 \%$ of the patients with prolactin-secreting adenomas. The two patients with hormonal hyper function in Group A (100\%) showed normalization in one patient and improvement $(>50 \%$ reduction) in the other. Regarding the three patients with hormonal hyper function in Group B, biochemical remission was achieved in all three patients (100\%).

Post-operative complications included new hormonal deficiency, DI, post-operative intracerebral hematoma $(\mathrm{ICH})$, CSF rhinorrhea, HCP, fits, and development of $3^{\text {rd }}$ nerve palsy (Figure 3 ). The incidence of complications in the whole study group was $61.9 \%$; being higher with the transcranial approach $(77.8 \%)$ than with the endoscopic transsphenoidal approach $(50 \%)$. However, the difference was not statistically significant $(p=0.367)$. There was a single mortality in this study which occurred in a patient in Group A. The patient did not recover well after surgery due to hypothalamic affection. CT brain showed a small frontal $\mathrm{ICH}$ that could not explain the poor conscious level and was managed conservatively. The patient further deteriorated and died 10 days later from chest infection and sepsis. Regarding the two patients with post-operative CSF rhinorrhea, one was managed conservatively and the leak stopped after 5 days, while the other patient needed endoscopic repair 7 days later with a stoppage of the leak. One patient with ICH was managed conservatively as previously mentioned, while the other patient was managed by surgical evacuation of the hematoma together with insertion of a ventriculoperitoneal shunt due to the presence of HCP, and the patient recovered well after surgery.

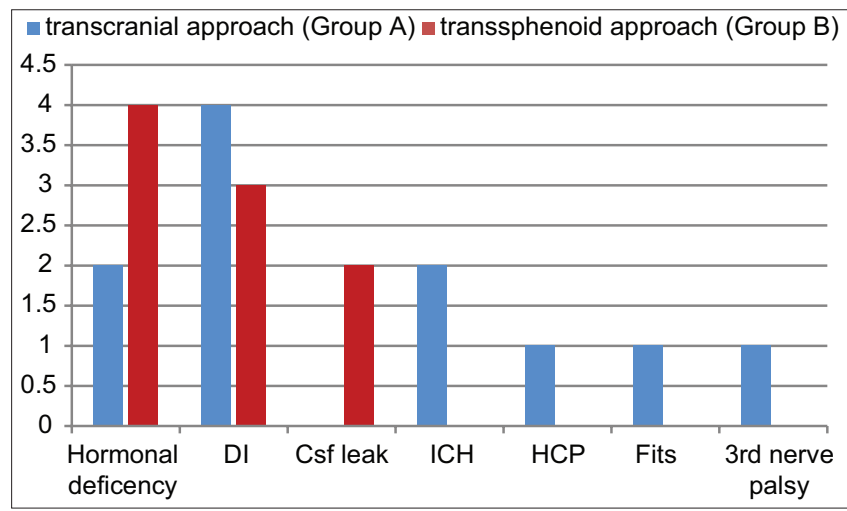

Figure 3: Chart showing different complications in both groups

\section{Discussion}

Many clinical series have addressed recurrent pituitary adenomas irrespective of the size [15], [16], while others have addressed giant pituitary adenomas whether fresh or recurrent [8], [9], [17]. However, there were no articles focusing on the management of recurrent giant adenomas in particular. In addition, in most of the above-mentioned articles the patients with "recurrent giant" tumors were not grouped together as a separate subset or group of patients, but were rather dispersed among the rest of the patients. Our study included 21 patients with recurrent giant pituitary adenomas operated on by transcranial (Group A) or endoscopic transsphenoidal (Group B) approaches, thus representing a unique series focusing on recurrent giant adenomas in particular. The patients' demographics, data of previous treatments, tumor types, and clinical presentation were comparable between both groups with no statistically significant difference.

The optimal surgical approach for giant adenomas is still debatable. Tumor's extensions represented an important factor in the choice of the surgical approach. Suprasellar extension was present in all our cases and it did not affect the choice of the approach unless a constriction was found at the diaphragm. Several authors considered significant suprasellar extension especially when dumbbell-shaped as an indication for transcranial surgery [11], [13], [14]. On the other hand, several authors did not consider this as an indication for transcranial surgery and have reported favorable outcomes with the endoscopic transsphenoidal approach (including expanded approaches) which provides a direct access along the tumor axis [8], [16], [18]. Cavernous sinus invasion was found in $28.6 \%$ of our cases, and its presence did not influence the choice of the approach in our study as well as in many other series as it presents a common limitation for radical tumor resection irrespective of the approach [8], [17], [19]. Four cases $(19 \%)$ had marked extensions into the middle and anterior cranial fossa and all were operated on by transcranial approaches. Similarly, several authors considered significant tumor extension into the middle or anterior fossa among the indications for transcranial approaches [11], [13], [14], [20]. On the other hand, de Divitiis et al. mentioned that adenomas with significant anterior or lateral extensions could be approached by expanded endoscopic approaches [21]. Koutourousiou et al. reported that tumors extending into the lateral cavernous sinus and the middle fossa could not be totally resected unless a transcranial approach was performed; however, they preferred a conservative approach and recommended managing these lesions with transsphenoidal approaches leaving a small residual [8].

Tumor consistency was another important factor in the choice of the surgical approach. De Divitiis et al. mentioned that fibrous adenomas could be approached by expanded endoscopic approaches [21]. Moreover, Jane et al. mentioned that firm tumor consistency did not have a consistently adverse effect or increase the complications of repeat transsphenoidal surgery [7]. 
Other authors argued that with the transsphenoidal approach it might be difficult to manage firm and fibrous adenomas especially when giant and recurrent with adhesions, as this could increase the morbidity from damage to surrounding structures, making a transcranial or a combined approach preferred in such adenomas [7], [13], [14], [20], [22], [23]. Thus, it was important to predict tumor consistency before surgery to help in the choice of the best approach. Firm consistency could be anticipated from different MRI sequences, history of the previous radiotherapy, and history of previous medical treatment [7], [20], [24], [25], [26].

Another additional important factor affecting the choice of the approach in recurrent cases was the previous surgical approach. Failure to achieve the goal of surgery through the transsphenoidal approach was considered as an indication for transcranial approaches by some authors [13], [22], [27], whereas other authors recommended repeat transsphenoidal surgery [18], [28]. In cases with a previous transsphenoidal approach, there might be anatomical landmark distortion adding more difficulty to the repeated transsphenoidal surgery; however, this can be overridden using frameless stereotaxy or intraoperative MRI [18], [29], [30]. In cases with previous transcranial approach, dense arachnoid adhesions and partial or complete absence of diaphragm may add to the risks and complications of transsphenoidal approach, including higher incidence of post-operative CSF leak [18], [31]. Similarly, if transcranial approach was performed following a transsphenoidal approach with inadequate sphenoid sinus obliteration, the probability of CSF rhinorrhea is high [27]. Several authors advocated the use of the endoscopic transsphenoidal approaches for all recurrent adenomas including giant tumors, irrespective of the primary approach [8], [15], [18]. Cavallo et al. reported that the endoscopic transsphenoidal approach following transcranial surgery allow using a naïve route in addition to obtaining an inverse view of the surgical field with accessibility to previously inaccessible tumor parts. However, their extent of resection was much lower in patients previously operated on by transcranial approaches [18]. Nishioka et al. reported the use of combined approaches for these recurrent giant cases irrespective of the previous approaches. The transcranial part of the combined approach was thought to be more helpful in management of the parasellar and high suprasellar parts [23].

Extent of tumor resection represents an important factor in the outcome assessment. More radical extent of resection leads to longer recurrence-free (progression-free) interval and better outcome. Several authors categorized the extent of resection of pituitary adenomas in various ways using different cutoffs for each category, thus making a uniform definition for the extent of resection non-applicable, and making comparisons with other authors about the achieved extent of resection difficult [8], [9], [12], [15, [16], [17], [18]. We achieved total or near-total resection in $28.6 \%$, subtotal resection in $38.1 \%$, and partial resection in $33.3 \%$ of all patients. The limitations to radical resection in our series included cavernous sinus extensions, significant anterior or middle fossa extensions, marked suprasellar extension into the third ventricle, and firm consistency. Similar limitations for radical resection were reported in several clinical series [8], [9], [17]. In cases with parasellar extension, our goal was to decompress the optic apparatus and reduce the tumor burden. The residual tumor was managed by radiosurgery, medical treatment, or followed up. Several studies encouraged safe excision of adenomas while leaving the cavernous portion for radiosurgery as long as an adequate distance $(>5 \mathrm{~mm}$ ) exists between the residual tumor and the optic apparatus [8], [11], [13], [32].

Nishioka et al. achieved total resection in $15.4 \%$, subtotal resection in $76.9 \%$, and partial resection in $7.7 \%$ of their 13 patients with recurrent adenomas $(>3 \mathrm{~cm}$ ) operated on by combined approach [23]. Using various surgical approaches, Han et al. achieved $>90 \%$ tumor resection in $55.6 \%$ of their patients with recurrent giant adenomas [9]. Koutourousiou et al. reported gross total resection, near-total resection, and partial resection in $6.2 \%, 18.8 \%$, and $75 \%$ of their patients with recurrent giant adenomas, respectively [8]. Nishioka et al. achieved total resection, subtotal resection with residue in the cavernous sinus, and subtotal or partial resection with residue outside the cavernous sinus in $13.5 \%, 54.1 \%$, and $32.4 \%$ of their recurrent patients, respectively [17]. The significantly reduced extent of resection reported by these authors in recurrent cases as compared to their extent of resection in fresh cases emphasizes the difficulty to achieve adequate extent of resection in these recurrent cases. Furthermore, the generally less favorable outcome following surgical resection of recurrent giant adenomas did not differ significantly among authors using different surgical approaches. Moreover, even the combined approaches did not achieve significantly better resection in management of these challenging tumors mostly due to multi-compartmental extensions particularly into the cavernous sinus.

Comparing both groups, the percentage of total and near-total resection was clearly higher in Group B; however, the difference was not statistically significant. The incidence of suprasellar extension and cavernous sinus invasion was comparable in both groups; however, marked tumor extensions into the middle or the anterior fossa were only found in Group A and fibrous tumors were more common in Group A, which might explain the difference between both groups regarding the extent of resection. Koutourousiou et al. analyzed their extent of resection according to tumor extensions and reported that tumor extensions into the anterior fossa, posterior fossa, or the third ventricle were associated with a lower incidence of gross total resection in comparison to the whole study group, with the lowest incidence being with tumors having anterior cranial fossa extensions [8]. In their systematic review, Komotar et al. found that 
gross total resection was achieved in $9.6 \%$ and $47.2 \%$ of the patients operated on by transcranial and endoscopic transsphenoidal approaches, respectively. Their findings are comparable to our results in both the transcranial and the transsphenoidal groups; however, not all of their included giant cases were recurrent [5]. On the other hand, Han et al. achieved $>90 \%$ resection of giant adenomas including recurrent cases in $75 \%$ (all three patients had gross total resection) and $76.7 \%$ (gross total resection in only one-third of them) of the cases following the transcranial and the transsphenoidal approaches, respectively [9].

Regarding the whole study group, visual improvement was achieved in $43.8 \%$ of the patients with pre-operative visual affection, with no visual deterioration in any patient. The rate of visual improvement in patients with giant adenomas (including some recurrent cases) having pre-operative visual affection in several series ranged between 53\% and $80 \%$, while the incidence of visual deterioration ranged between $0 \%$ and $4.8 \%$ [4], [8], [9], [23]. In the above-mentioned series, there was no data regarding the outcome in recurrent giant cases in particular. The lower incidence of visual improvement in our series in comparison with other series might be due to their inclusion of both recurrent and fresh giant adenomas while our series included only recurrent giant cases. Nishioka et al. reported visual improvement in $79.1 \%$ and visual deterioration in $3.6 \%$ of their patients, however, when they analyzed the subgroup of patients with stationary vision or visual deterioration they found that this occurred in $14.1 \%$ with fresh adenomas and in $37.5 \%$ with recurrent adenomas which goes with our findings regarding the lower incidence of visual improvement in recurrent giant cases [17].

Visual improvement was achieved in $28.6 \%$ in Group A and in 55.6\% in Group B. In Han et al. series, visual improvement was achieved in $50 \%$ and $81.4 \%$ of the patients operated on by transcranial and transsphenoidal approaches, respectively, which goes with our findings that visual improvement was higher in the transsphenoidal group than with the transcranial group [9]. Similarly, Komotar et al. in their systematic review reported much better results with the endoscopic transsphenoidal approach $(91.1 \%$ improvement with no deterioration) as compared to the transcranial approaches (40\% improvement and $22.9 \%$ deterioration). This might be due to the selection of transcranial approaches for the more complicated cases [5].

Regarding functioning adenomas, normalization of the hormonal level was achieved in $100 \%$ of the patients with $\mathrm{GH}$-secreting adenomas and in $66.7 \%$ of the patients with prolactin-secreting adenomas. Subgroup analysis showed a $50 \%$ remission rate in the transcranial group and $100 \%$ remission rate in the transsphenoidal group. Han et al. achieved endocrinological remission in three of their five patients $(60 \%)$ with $\mathrm{GH}$-secreting adenomas operated on by the transsphenoidal approach and in the single patient $(100 \%)$ operated on by combined approach, while it was not achieved in any of the two patients with prolactinomas operated on by the transsphenoidal approach [9]. In Wang et al. series of 36 giant adenomas, improvement (normalization or reduction of hormone level by $>25 \%$ ) occurred in $71.4 \%$ of prolactinomas and in all three cases of $\mathrm{GH}$-secreting and TSH-secreting adenomas; however, there were no recurrent cases in their series [33].

Surgery in recurrent cases has a higher risk of complications and the giant size adds more to the risk. Complications rate in our series $(61.9 \%)$ was higher than that reported in several clinical series which might be explained by the inclusion criteria in each study, with our study including only recurrent giant adenomas in contrast to the other studies. Furthermore, some clinical series did not include the newly developed postoperative pituitary insufficiency in their complications. Nishioka et al. reported complications apart from pituitary dysfunction in $46.2 \%$ of their patients with recurrent adenomas $>3 \mathrm{~cm}$ and they stated that these complications were transient [23]. Tajudeen et al. reported minor complications in $22 \%$ of their patients; however, only six of their 27 recurrent adenomas were giant [15]. Nishioka et al. reported permanent neurological deficits and permanent hypopituitarism and DI in only $24.3 \%$ of their patients with recurrent giant adenomas, however, they reported the occurrence of other complications, including visual deterioration, CSF leak, and meningitis in their patients but their incidence in recurrent cases was not specified [17].

The incidence of complications was higher with the transcranial approach $(77.8 \%)$ than with the endoscopic transsphenoidal approach (50\%) with no statistically significant difference. These results might need cautious interpretation as the transcranial approach was reserved for more extensive and challenging tumors which are more likely to have post-operative complications. Han et al. reported a much higher incidence of pituitary insufficiency, DI, and electrolyte imbalance following the transcranial approach and higher incidence of CSF leak and meningitis following the transsphenoidal approach [9]. Komotar et al. reported no complications in only $17.5 \%$ of the patients operated on by transcranial approaches, which is close to our complication rate in the transcranial group. Reported complications included hypopituitarism, permanent DI, CSF leak, and cerebral infarction. Mortality was reported in $10.6 \%$ of the transcranial cases which is similar to our results. Regarding the endoscopic transsphenoidal approach, much lower complication rate was reported $(13 \%$ of the cases) and complications included DI, sinusitis, pulmonary embolism, and hemorrhage [5].

\section{Study limitations}

Limitations included the small number of cases in each group which is due to the low incidence 
of recurrent giant adenomas, the difference between both groups as regards the tumors' extensions which may interfere with the choice of the approach and the results and the non-randomization of patients to both groups. In addition, not all cases were operated on by the same surgeon which might affect the results. Future randomized studies with a larger number of patients and longer follow-up periods are recommended.

\section{Conclusion}

The endoscopic transsphenoidal approach is associated with a higher extent of tumor resection, better rates of visual improvement and endocrinological remission, and lower incidence of complications as compared to the transcranial approach in the management of recurrent giant pituitary adenomas. However, these superior results might be affected by the more complexity of the cases selected for the transcranial approach. Thus, the endoscopic transsphenoidal approach should be considered as the first choice for these challenging lesions, with the transcranial approach reserved for some lesions with marked lateral or anterior extensions, fibrous tumors, and after the failure of the endoscopic transsphenoidal approach.

\section{References}

1. Garibi J, Pomposo I, Villar G, Gaztambide S. Giant pituitary adenomas: Clinical characteristics and surgical results. $\mathrm{Br} J$ Neurosurg 2002;16(2):133-9. https://doi. org/10.1080/02688690220131723

PMid:12046731

2. Mortini P, Barzaghi R, Losa M, Boari N, Giovanelli M. Surgical treatment of giant pituitary adenomas: Strategies and results in a series of 95 consecutive patients. Neurosurgery 2007;60(6):9931002. https://doi.org/10.1227/01.neu.0000255459.14764.ba PMid: 17538372

3. Agrawal A, Cincu R, Goel A. Current concepts and controversies in the management of non-functioning giant pituitary macroadenomas. Clin Neurol Neurosurg 2007;109(8):645-50. https://doi.org/10.1016/j.clineuro.2007.06.007 PMid: 17686573

4. Sinha S, Sharma BS. Giant pituitary adenomas-an enigma revisited. Microsurgical treatment strategies and outcome in a series of 250 patients. Br J Neurosurg 2010;24(1):31-9. https:// doi.org/10.3109/02688690903370305

PMid:20158350

5. Komotar RJ, Starke RM, Raper DM, Anand VK, Schwartz TH. Endoscopic endonasal compared with microscopic transsphenoidal and open transcranial resection of giant pituitary adenomas. Pituitary 2012;15(2):150-9. https://doi. org/10.1007/s11102-011-0359-3

PMid:22038033
6. Vance ML. Diagnosis, management, and prognosis of pituitary tumors. In: Thapar K, Kovacs K, Scheithauer BW, Lloyd RV, editors. Diagnosis and Management of Pituitary Tumors. Totowa: Humana Press; 2001. p. 165-72. https://doi. org/10.1385/1592592171

7. Jane JA Jr., Thapar K, Laws ER Jr. Pituitary tumors: Functioning and nonfunctioning. In: Winn HR, editor. Youmans Neurological Surgery. Philadelphia, PA: Elsevier Saunders; 2011. p.1476-510. https://doi.org/10.1016/b978-1-4160-5316-3.00137-4

8. Koutourousiou M, Gardner PA, Fernandez-Miranda JC, Paluzzi A, Wang EW, Snyderman CH. Endoscopic endonasal surgery for giant pituitary adenomas: Advantages and limitations. J Neurosurg 2013;118(3):621-31. https://doi. org/10.3171/2012.11.jns121190

PMid:23289816

9. Han S, Gao W, Jing Z, Wang Y, Wu A. How to deal with giant pituitary adenomas: Transsphenoidal or transcranial, simultaneous or two-staged? J Neurooncol 2017;132(2):313-21. https://doi.org/10.1007/s11060-017-2371-6

PMid:28074324

10. Roelfsema F, Biermasz NR, Pereira AM. Clinical factors involved in the recurrence of pituitary adenomas after surgical remission: A structured review and meta-analysis. Pituitary 2012;15(1):71-83. https://doi.org/10.1007/s11102-011-0347-7 PMid:21918830

11. Pratheesh R, Rajaratnam S, Prabhu K, Mani SE, Chacko G, Chacko AG. The current role of transcranial surgery in the management of pituitary adenomas. Pituitary 2013;16(4):419-34. https://doi.org/10.1007/s11102-012-0439-z PMid:23076713

12. D'Ambrosio AL, Syed ON, Grobelny BT, Freda PU, Wardlaw S, Bruce JN. Simultaneous above and below approach to giant pituitary adenomas: Surgical strategies and long-term follow-up. Pituitary 2009;12(3):217-25. https://doi.org/10.1007/ s11102-009-0171-5 PMid:19242807

13. Youssef AS, Agazzi S, van Loveren HR. Transcranial surgery for pituitary adenomas. Oper Neurosurg. 2005;57(Suppl 1):168-75 https://doi.org/10.1227/01.neu.0000163602.05663.86

14. Buchfelder $M$, Kreutzer J. Transcranial surgery for pituitary adenomas. Pituitary. 2008;11(4):375-84. https://doi.org/10.1007/ s11102-008-0120-8

15. Tajudeen BA, Mundi J, Suh JD, Bergsneider M, Wang MB Endoscopic endonasal surgery for recurrent pituitary tumors: Technical challenges to the surgical approach. J Neurol Surg B Skull Base 2015;76(1):50-6. https://doi. org/10.1055/s-0034-1383856

PMid:25685650

16. Do H, Kshettry VR, Siu A, Belinsky I, Farrell CJ, Nyquist G, et al. Extent of resection, visual, and endocrinologic outcomes for endoscopic endonasal surgery for recurrent pituitary adenomas. World Neurosurg 2017;102:35-41. https://doi.org/10.1016/j. wneu.2017.02.131 PMid:28286277

17. Nishioka H, Hara $T$, Nagata $Y$, Fukuhara N, YamaguchiOkada M, Yamada S. Inherent tumor characteristics that limit effective and safe resection of giant nonfunctioning pituitary adenomas. World Neurosurg 2017;106:645-52. https://doi. org/10.1016/j.wneu.2017.07.043

PMid:28735124

18. Cavallo LM, Solari D, Tasiou A, Esposito F, de Angelis M, D'Enza Al, et al. Endoscopic endonasal transsphenoidal removal of recurrent and regrowing pituitary adenomas: Experience on a 59-patient series. World Neurosurg 2013;80(3-4):342-50. https://doi.org/10.1016/j.wneu.2012.10.008

PMid:23046913 
19. Rudnik A, Zawadzki T, Gałuszka-Ignasiak B, Bazowski P, Duda I, Wojtacha M, et al. Endoscopic transsphenoida treatment in recurrent and residual pituitary adenomas first experience. Minim Invasive Neurosurg 2006;49(1):10-4. https:// doi.org/10.1055/s-2006-932126

\section{PMid:16547875}

20. Thapar K, Laws ER Jr. Pituitary surgery. In Thapar K, Kovacs K Scheithauer BW, Lloyd RV, editors. Diagnosis and Management of Pituitary Tumors. Totowa: Humana Press; 2001. p. 225-46. https://doi.org/10.1385/1-59259-217-1:225

21. de Divitiis $E$, de Divitiis $O$. Surgery for large pituitary adenomas: What is the best way? World Neurosurg 2012;77(3-4):448-50. https://doi.org/10.1016/j.wneu.2011.09.044 PMid:22120242

22. Zada G, Du R, Laws ER Jr. Defining the "edge of the envelope": patient selection in treating complex sellar-based neoplasms via transsphenoidal versus open craniotomy. J Neurosurg 2011;114:286-300. https://doi.org/10.3171/2010.8.jns10520 PMid:20815698

23. Nishioka $\mathrm{H}$, Hara $\mathrm{T}$, Usui $\mathrm{M}$, Fukuhara $\mathrm{N}$, Yamada $\mathrm{S}$. Simultaneous combined supra-infrasellar approach for giant/ large multilobulated pituitary adenomas. World Neurosurg 2012;77(3-4):533-9. https://doi.org/10.1016/j.wneu.2011.07.013 PMid:22120331

24. Pierallini A, Caramia F, Falcone C, Tinelli E, Paonessa A Ciddio $A B$, et al. Pituitary macroadenomas: preoperative evaluation of consistency with diffusion-weighted MR imaging-initial experience. Radiology 2006;239(1):223-31. https://doi. org/10.1148/radiol.2383042204

PMid:16452397

25. Yamamoto J, Kakeda S, Shimajiri S, Takahashi M, Watanabe K Kai Y, et al. Tumor consistency of pituitary macroadenomas: Predictive analysis on the basis of imaging features with contrast-enhanced 3D FIESTA at 3T. AJNR Am J Neuroradio 2014;35(2):297-303. https://doi.org/10.3174/ajnr.a3667 PMid:23928139

26. Smith KA, Leever JD, Chamoun RB. Prediction of Consistency of Pituitary Adenomas by Magnetic Resonance Imaging. J Neurol Surg B Skull Base 2015;76(5):340-3. doi.org/10.1055/s-0035-1549005

\section{PMid:26401474}

27. Recinos PF, Goodwin CR, Brem H, Quiñones-Hinojosa A Transcranial surgery for pituitary macroadenomas. In: Quinones-Hinojosa A, editor. Schmidek and Sweet Operative Neurosurgical Techniques: Indications, Methods, and Results. Philadelphia. PA: Elsevier Saunders; 2012. p. 280-91. https:// doi.org/10.1016/b978-1-4160-6839-6.10023-1

28. Chang EF, Sughrue ME, Zada G, Wilson CB, Blevins LS Jr., Kunwar S. Long term outcome following repeat transsphenoidal surgery for recurrent endocrine-inactive pituitary adenomas. Pituitary 2010;13(3):223-9. https://doi.org/10.1007/ s11102-010-0221-z

PMid:20217484

29. Jagannathan J, Prevedello DM, Ayer VS, Dumont AS, Jane JA Jr., Laws ER. Computer-assisted frameless stereotaxy in transsphenoidal surgery at a single institution: Review of 176 cases. Neurosurg Focus 2006;20(2):E9. https://doi.org/10.3171/ foc. 2006.20 .2 .10

PMid:16512660

30. Laws ER. The endoscopic endonasal approach for recurrent pituitary lesions. World Neurosurg 2013;80(3-4):272-3. https:// doi.org/10.1016/j.wneu.2012.11.041 PMid:23165173

31. Laws ER Jr., Fode NC, Redmond MJ. Transsphenoidal surgery following unsuccessful prior therapy. An assessment of benefits and risks in 158 patients. J Neurosurg 1985;63(6):823-9. https:// doi.org/10.3171/jns.1985.63.6.0823

PMid:2997414

32. Pollock BE, Kondziolka D, Lunsford LD, Flickinger JC. Stereotactic radiosurgery for pituitary adenomas: Imaging, visual and endocrine results. Acta Neurochir Suppl 1994;62:33-8. https://doi.org/10.1007/978-3-7091-9371-6_7 PMid:7717132

33. Wang S, Lin S, Wei L, Zhao L, Huang Y. Analysis of operative efficacy for giant pituitary adenoma. BMC Surg 2014;14:59. https://doi.org/10.1186/1471-2482-14-59

PMid:25163653 